\title{
Susceptibility of Treponema pallidum to the toxic products of oxygen reduction and the non- treponemal nature of its catalase
}

\author{
B STEINER, G H W WONG, AND S GRAVES \\ From the Department of Microbiology, Monash University Medical School, Alfred Hospital, Prahran, \\ Victoria, Australia
}

SUMMARY We examined the sensitivity of Treponema pallidum (Nichols strain) to toxic products of oxygen reduction. $T$ pallidum was sensitive to hydrogen peroxide at concentrations similar to those to which obligate anaerobes are sensitive. Accelerated death of $T$ pallidum occurred at hydrogen peroxide concentrations below $50 \mu \mathrm{mol} / \mathrm{l}$. Agents protective against hydrogen peroxide and the hydroxyl free radical (catalase, peroxidase, and mannitol) significantly enhanced treponemal survival in vitro under all three conditions of aerobiosis tested - that is, air, $3 \%$ oxygen, and $3 \%$ oxygen in conjunction with a reduced medium. Superoxide dismutase (which provides protection against superoxide radicals) did not enhance treponemal survival in normal media. When superoxide radicals were generated in the medium by means of a xanthine and xanthine oxidase system, however, the enzyme did protect $T$ pallidum. A possible toxic involvement of singlet oxygen was also indicated by enhanced treponemal survival in air in the presence of histidine. Extracts of $T$ pallidum from infected rabbit testes showed catalase activity which, on polyacrylamide gel electrophoresis, had the same relative mobility as purified rabbit catalase. The treponemal catalase activity was neutralised by anti rabbit catalase antiserum (raised in guinea pigs). This confirmed that the catalase was of rabbit origin and not an endogenous enzyme of $T$ pallidum. We discuss the relation of these results to the obligate parasitism of $T$ pallidum.

\section{Introduction}

Several studies have shown the utilisation of oxygen by Treponema pallidum,,$^{1-3}$ although the organism survives longest in low levels of oxygen ${ }^{45}$ and in a highly reduced environment. ${ }^{6}$ It has been grown in tissue culture provided that atmospheric oxygen tensions are below $10 \%$ and a reducing agent is present. ${ }^{7}$ In vitro $T$ pallidum seems unable to cope with the diffusion of oxygen from the atmosphere into the medium, which has led to the incorporation of various reducing agents in treponemal maintenance medium. ${ }^{8}$

(This work was presented in a preliminary form at the 12th International Union for Biochemistry Meeting in Perth, Western Australia, August 1982).

Address for reprints: Dr B Steiner, Department of Pathology and Laboratory Medicine, Medical School, University of Texas, Health Science Center, Houston, Texas 77025, USA

Accepted for publication 21 June 1983
Although tissue culture cells have been shown to help $T$ pallidum survival in vitro, ${ }^{49}$ the basis for this is unknown. The eucaryotic cells may enhance treponemal survival by detoxifying toxic products generated by oxygen (such as hydrogen peroxide, hydroxyl free radical, and singlet oxygen), or by synthesising oxygen labile components, such as mucopolysaccharides, which might then be incorporated into the extracellular material of $T$ pallidum. ${ }^{10}$ Continued survival or growth may thus occur under conditions that would quickly kill treponemes not associated with host cells. The ability to detoxify reduction products generated by oxygen is one of the clearest differences between aerobes and anaerobes. Both catalase and peroxidase are considered to be important for the survival of bacteria under aerobic conditions. ${ }^{11}$ Recent work has implicated the superoxide free radical as a major toxic oxygen species; against which both aerobes and aerotolerant anaerobes have detoxifying mechanisms. ${ }^{12-14}$ As mammalian cells produce enzymes such as catalase and superoxide 
dismutase, their ability to detoxify oxygen reduction products may be one of the reasons that they help $T$ pallidum survival in vitro. Oxygen reduction products could kill $T$ pallidum even when reducing agents are present. Reducing agents can generate reactive compounds, such as hydrogen peroxide and hydroxyl free radicals, in bacteriological media when they are exposed to molecular oxygen. ${ }^{15} 16 \mathrm{We}$ report the effects of oxygen reduction products and various oxygen protective agents on the survival of $T$ palli$d u m$ in vitro. We also show that the catalase activity associated with $T$ pallidum ${ }^{3} 17$ is caused by rabbit catalase and not an endogenous treponemal enzyme.

\section{Materials and Methods}

\section{MAINTENANCE AND HARVESTING OF \\ TREPONEMA PALLIDUM}

$T$ pallidum (Nichols strain) was maintained by intratesticular inoculation in adult rabbits. Inflammatory reactions were reduced by injections of methylprednisolone acetate $4 \mathrm{mg} / \mathrm{kg}$ body weight on days 2 and 9 after infection with $T$ pallidum. ${ }^{18}$

Rabbits were killed by intravenous injection of $3 \mathrm{ml}$ sodium pentobarbitone $(200 \mathrm{mg} / \mathrm{ml})$ 10-12 days after infection, when orchitis was maximal. The testes were removed aseptically, minced, placed in about $100 \mathrm{ml}$ of medium appropriate for the experiment being performed (see below), and shaken for 15 minutes. The suspension was centrifuged at $1000 \times g$ for 10 minutes and the supernatant, containing approximately $10^{7}$ treponemes $/ \mathrm{ml}$, used as inoculum. In preliminary experiments an attempt was made to separate the treponemes from tissue cells by filtration through a $0.8 \mu \mathrm{m}$ nucleopore filter. ${ }^{19}$ In general survival of the filtered treponemes was noticeably less than when $T$ pallidum was separated from tissue debris by centrifugation. As centrifugation is the most commonly used technique and has been used to separate $T$ pallidum from tissue cells in labelling studies, ${ }^{5}$ we used it for separation throughout these experiments.

Oxygen protective agents were made up as concentrated solutions immediately before use and sterilised by filtration through $0.45 \mu \mathrm{m}$ Amicon micropore filters. Appropriate volumes of the solutions were added to the medium immediately before inoculation with $T$ pallidum suspension, to $1 \mathrm{ml}$ of which $9 \mathrm{ml}$ medium was added, giving a final concentration of approximately $10^{6}$ treponemes $/ \mathrm{ml}$. In experiments with reduced medium, it was held under nitrogen while being dispensed into tubes with cotton wool plugs. The tubes were incubated in an atmosphere of $3 \%$ oxygen in nitrogen. These conditions allowed slow diffusion of oxygen into the medium over the course of the experiment. Redox potentials were measured to ensure they were in the +50 to $-50 \mathrm{mv}$ Eh range which permitted a high $T$ pallidum survival rate in the medium used. ${ }^{6}$

\section{PREPARATION OF MEDIUM}

Aerobic experiments, and some performed in $3 \%$ oxygen, were carried out in Eagle's essential minimal medium containing $20 \%$ fetal calf serum and $20 \mathrm{~mol} / 1 \mathrm{~N}$-2-hydroxyethylpiperazine- $\mathrm{N}^{\prime}$-2-ethanesulphonic acid (HEPES) buffer. Experiments were performed using $20 \mathrm{ml}$ screw capped bottles as culture vessels containing $10 \mathrm{ml}$ of medium. Experiments in 3\% oxygen were performed in the same medium but with added reducing agents, such as reduced glutathione $7.8 \mathrm{~mol} / \mathrm{l}$, cysteine $10 \mathrm{~mol} / \mathrm{l}$, and dithiothreitol $1 \mathrm{~mol} / \mathrm{l})$. The method of preparing reduced medium has been described in detail previously, ${ }^{6}$ and $10 \mathrm{ml}$ was inoculated into $23 \times 150 \mathrm{~mm}$ tubes plugged with a cotton wool stopper to allow for rapid equilibration between the medium and atmosphere. Tubes were incubated in a germ free anaerobic hood in which the atmosphere contained $3 \%$ oxygen and $97 \%$ nitrogen as previously described $^{6}$ at a temperature of $34^{\circ} \mathrm{C}$ in all experiments.

\section{SURVIVAL OF TPALLIDUM}

Survival of $T$ pallidum was measured in two ways: a) by randomly observing 50-100 treponemes/culture sample to establish the percentage motility of the culture, ${ }^{6}$ and b) by intradermal inoculation of $0.1 \mathrm{ml}$ of culture into each of four to six sites/rabbit on the shaved backs of two rabbits, ${ }^{6}$ following the course of infection, and estimating the latent period to find the virulence for rabbits. There was an inverse relation between the latent period of infection and the number of viable $T$ pallidum remaining in the culture. $^{20}$

PRODUCTION AND MEASUREMENT OF OXYGEN REDUCTION PRODUCTS IN THE MEDIUM

All experiments showing the toxicity of oxygen reduction products were carried out under aerobic conditions. Reagent grade hydrogen peroxide was prepared as a $10 \mathrm{mmol} / 1$ solution. Appropriate volumes were then added to the medium to give the required final concentrations. Superoxide anions were produced using the xanthine and xanthine oxidase system described by Murray and Cohn, ${ }^{21}$ which contained $1.5 \times 10^{-4} \mathrm{~mol} / 1$ xanthine and $25 \mathrm{IU} / \mathrm{l}$ xanthine oxidase. It produced both hydrogen peroxide and superoxide anions. ${ }^{21}$ The concentration of hydrogen peroxide present in the control medium was measured with an oxygen electrode (Model LR-30, Titron, Melbourne, Australia) using the technique of Dempsey et al. ${ }^{22}$ 
MEASUREMENT OF ENZYME ACTIVITIES

The activity of catalase was determined by measuring the disappearance of hydrogen peroxide in aerobic medium using a spectrophotometer at $240 \mathrm{~nm} .{ }^{23}$ In the reduced medium absorption at $240 \mathrm{~nm}$ by the reducing agents containing sulphide was such that a 1:5 dilution of the reaction mixture was required before the assay was satisfactory. Enzyme activity was seen at all concentrations of catalase but could be accurately measured only in medium containing more than $200 \mathrm{IU} / \mathrm{ml}$ of catalase activity (one IU decomposes $0.1 \mathrm{mmol} / 1$ hydrogen peroxide a minute at $30^{\circ} \mathrm{C}$ ). This higher concentration of catalase was used in experiments performed in highly reduced media.

Superoxide dismutase activity was measured by the inhibition of pyrogallol oxidation, 24 that of peroxidase by using guaicol as the hydrogen donor, ${ }^{25}$ and xanthine oxidase was detected by the oxidation of xanthine using the method of Bergmeyer ${ }^{26}$ but without gelatin. This method detects superoxide anions formed by the reduction of nitrobluetetrazolium. The assay method was thus able to show that the system was producing oxygen reduction products in the medium.

PREPARATION OF T PALLIDUM EXTRACTS AND MEASUREMENT OF CATALASE ACTIVITY

Cell free extracts of $T$ pallidum were prepared for assaying catalase activity by initially separating the micro-organisms from rabbit testicular cells by centrifuging the crude testicular preparation twice at $500 \times g$ for 10 minutes. The treponemes were then pelleted at $12000 \times g$ for 20 minutes and washed twice in $20 \mathrm{ml}$ phosphate buffered saline. Samples were resuspended to approximately $10^{\circ}$ trepone$\mathrm{mes} / \mathrm{ml}$ and sonicated in a Soniprep MSE ultrasonic disintegrator (15 amplitude) using six 15 second pulses; the sonicator probe was cooled in ice after each pulse. Samples were centrifuged at $12000 \times g$ for $\mathbf{2 0}$ minutes to remove debris, and the supernatant concentrated tenfold by negative pressure dialysis. The extracts from five rabbits yielded $1 \mathrm{ml}$ concentrated sonicated $T$ pallidum extract. Samples were used immediately or frozen at $-70^{\circ} \mathrm{C}$ until used. Extracts prepared in a similar way from other bacteria and mammalian cells were used for comparison of their catalase activity with that of $T$ pallidum. Catalase activity was measured using a spectrophotometer. ${ }^{23}$ Total protein concentration was measured by the method of Lowry et al ${ }^{27}$ using bovine serum albumin as the standard. Disc gel electrophoresis was performed at $4 \mathrm{~mA} /$ tube by the method of Davis ${ }^{28}$ except that both the stacking and separating gels were polymerised with ammonium persulphate. Staining for catalase was performed by the method of Woodbury et al. ${ }^{29}$
PREPARATION OF ANTI RABBIT CATALASE ANTIBODY AND NEUTRALISATION ASSAYS Rabbit catalase was partially purified from uninfected rabbit erythrocytes ${ }^{30}$ and used to produce $\stackrel{\vec{S}}{\rightarrow}$ anti rabbit catalase antibodies in a guinea pig. Erythrocytes from $100 \mathrm{ml}$ of uninfected rabbit blood were washed twice in $0.9 \%$ sodium chloride and lysed by a 15 second pulse on the MSE sonicator as described above. The haemoglobin was precipitated with chloroform and ethanol in a 1:3 ratio and discarded after centrifugation. The chloroform and ethanol were evaporated, and the extract was dialysed overnight against distilled water. It was then acidified to $\mathrm{pH} 4 \cdot 0$ with $2 \mathrm{~mol} / \mathrm{l}$ acetate (pH $4 \cdot 0$ ) and the precipitate discarded. The $\mathrm{pH}$ was brought to 6.0 with $0.1 \mathrm{~mol} / 1$ phosphate (pH 6.0). Two sequential acetone precipitations were then carried out $(6 \mathrm{ml}$ and $5 \mathrm{ml} / 10 \mathrm{ml}$ extract) and the precipitates discarded. After evaporation of the acetone the extract consisted of more than $50 \%$ catalase as determined by polyacrylamide gel electrophoresis. This extract was used to immunise a guinea pig. The partially purified catalase was mixed with an equal volume of Freund's complete adjuvant, and guinea pigs were injected twice intramuscularly at 14 day intervals.

Fifty days after the first injection the guinea pigs were bled by cardiac puncture and the serum collected. Serum was also collected from a normal rabbit and a rabbit infected 120 days previously with $T$ pallidum. Samples of $50 \mu \mathrm{l}$ of these sera were mixed with $50 \mu$ l of catalase containing extracts of rabbit erythrocytes, $T$ pallidum, or $E$ coli $K 12$ in five $50 \mathrm{~mm}$ precipitant tubes. The tubes were incubated at $37^{\circ} \mathrm{C}$ for 30 minutes and then overnight at $4^{\circ} \mathrm{C}$ to allow for maximum reaction between antigen and antibody. Neutralisation was measured by electrophoresis of the samples on gels as described above and by staining for catalase. Controls contained phosphate buffered saline substituted for immune serum.

\section{CHEMICALS}

Univar grade hydrogen peroxide ( $30 \%$ solution) was bought from Ajax Chemical Co, Sydney, Australia. Two grades of catalase were used (Sigma, St Louis, Missouri, USA). The activity of the lower grade was $2000-5000 \mathrm{IU} / \mathrm{mg}$, and that of the higher grade $30000-40000 \mathrm{IU} / \mathrm{mg}$ protein. Neither grade gave better treponemal survival, the effect being wholly dependent on IU/ml enzyme activity in the medium. Xanthine oxidase, horseradish peroxidase, superoxide dismutase, and trypsin were all bought from Sigma. All other chemicals were of reagent grade and were purchased from Sigma or British Drug Houses (Poole, United Kingdom). 
Results

TOXICITY OF OXYGEN REDUCTION PRODUCTS Treponemes exposed to hydrogen peroxide concentrations of $50 \mu \mathrm{mol} / 1$ and $100 \mu \mathrm{mol} / 1$ lost motility more rapidly than did the aerobic control (Fig 1). Cultures containing $10 \mu \mathrm{mol} / \mathrm{l}$ or $25 \mu \mathrm{mol} / \mathrm{l}$ hydrogen peroxide did not differ from the aerobic control (data not shown). The toxicity of added hydrogen peroxide was reversed when catalase was present at $200 \mathrm{IU} / \mathrm{ml}$ (Fig 1). The aerobic medium contained about $20 \mu \mathrm{mol} / 1$ hydrogen peroxide at the end of four hours, as determined by the oxygen electrode, even when none was added exogenously (data not shown).

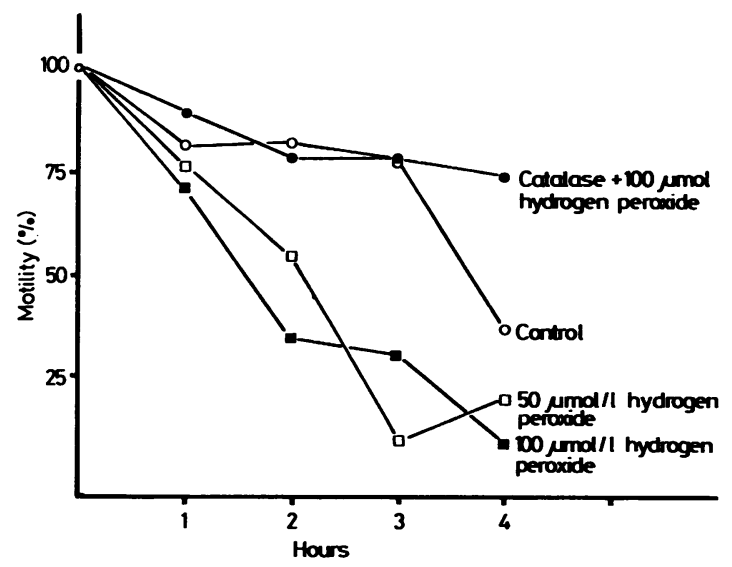

FIG 1 Effect of hydrogen peroxide on the motility of $T$ pallidum under aerobic conditions.

Table I shows the survival of $T$ pallidum in the presence of a xanthine and xanthine oxidase system, which generates both hydrogen peroxide and superoxide anions, ${ }^{21}$ under atmospheric conditions. The enzyme was fully active in the medium used, as demonstrated by its ability to reduce nitrobluetetrazolium (this procedure actually measures superoxide anions formed during the oxidation of xanthine). Preliminary experiments, using motility as a measure of survival, showed that only the complete system was harmful to $T$ pallidum; xanthine or xanthine oxidase alone had no effect. When the complete system was used, catalase, superoxide dismutase, and mannitol all protected against the toxicity generated in this system, as measured by survival of virulent treponemes, with no noticeable difference between the protective effect of catalase and superoxide dismutase. Only catalase substantially enhanced retention of treponeme motility (data not shown). When catalase and superoxide dismutase were heated at $100^{\circ} \mathrm{C}$ for 10 minutes and the treponemes assayed after four hours in vitro, the protective effects of the enzymes were significantly (p<0.05) reduced (table 1). The eight to ten day difference in latent period between the boiled and native enzymes seen after four hours in vitro is equal to approximately a three $\log$ difference in the number of virulent $T$ pallidum left in the culture. ${ }^{20}$ The boiled enzymes showed no activity when assayed using a spectrophotometer.

\section{PROTECTION BY OXYGEN DETOXIFYING AGENTS UNDER UNREDUCED CONDITIONS}

Table II shows the protective effect under atmospheric conditions of catalase, superoxide dismutase, mannitol, and histidine compared with the unprotected control. Catalase was highly protective except when boiled, and testing at three concentrations (100 $\mathrm{IU} / \mathrm{ml}, 200 \mathrm{IU} / \mathrm{ml}$ and $400 \mathrm{IU} / \mathrm{ml}$ ) showed that the two higher concentrations gave the best protection. Mannitol was consistently protective judging by the virulence of $T$ pallidum but not by measurement of treponemal motility (data not shown), which indicates that the latter is a less sensitive assay. The effect of superoxide dismutase was erratic; it was actually detrimental to treponemal survival in many

TABLE I Effects of various oxygen detoxifying agents on $T$ pallidum survival in the presence of a superoxide anion generating system containing xanthine and xanthine oxidase under aerobic conditions

\begin{tabular}{|c|c|c|c|}
\hline \multirow[b]{2}{*}{ Oxygen detoxifying agents } & \multicolumn{3}{|c|}{$\begin{array}{l}\text { Latent periods of syphilitic infection (days between inoculation with } \\
\text { treponemal culture and occurrence of skin lesions) (mean (SD) of four } \\
\text { experiments) after in vitro holding periods of: }\end{array}$} \\
\hline & 0 hours & 2 hours & 4 hours \\
\hline $\begin{array}{l}\text { Control (no detoxifying agents) } \\
\text { Catalase } 400 \text { units } / \mathrm{ml} \\
\text { heated at } 100^{\circ} \mathrm{C} \text { for } 10 \text { minutes } \\
\text { Superoxide dismutase } 60 \text { units } / \mathrm{ml} \\
\text { heated at } 100^{\circ} \mathrm{C} \text { for } 10 \text { minutes } \\
\text { Mannitol } 100 \mathrm{mmol} / 1\end{array}$ & $\begin{array}{l}9 \cdot 2(0 \cdot 5) \\
9 \cdot 2(0 \cdot 5) \\
9 \cdot 2(0 \cdot 5) \\
9 \cdot 2(0 \cdot 5)\end{array}$ & $\begin{array}{r}9 \cdot 5(1 \cdot 0) \\
10 \cdot 0(1 \cdot 2) \\
11 \cdot 0(2 \cdot 0) \\
10 \cdot 0(1 \cdot 2) \\
11 \cdot 3(2 \cdot 1) \\
9 \cdot 5(0 \cdot 6)\end{array}$ & $\begin{array}{l}\text { NL } \\
11 \cdot 8(0 \cdot 5)^{*} \\
21 \cdot 8(0 \cdot 8) \\
13 \cdot 0(0 \cdot 8)^{*} \\
21 \cdot 0(0 \cdot 8) \\
16 \cdot 5(0 \cdot 6)^{*}\end{array}$ \\
\hline
\end{tabular}

NL = no lesions at 4 inoculation sites; $*=$ significantly $(p<0-05)$ higher survival rate than in control. 
TA.BLE II Effects of various oxygen detoxifying agents on $T$ pallidum survival under aerobic conditions

Latent periods of syphilitic infection (days between inoculation with treponemal culture and occurrence of skin lesions) (mean (SD) of four experiments) after in vitro holding periods of:

\begin{tabular}{llll} 
Oxygen detoxifying agents & 0 hours & $2 \cdot 5$ hours & 5 hours \\
\hline Control (no detoxifying agents) & $8 \cdot 2(0 \cdot 9)$ & $9 \cdot 6(1 \cdot 5)$ & $14 \cdot 5(1 \cdot 7)$ \\
Catalase 400 units/ml & $8 \cdot 2(0 \cdot 9)$ & $8 \cdot 4(0 \cdot 5)$ & $9 \cdot 6(1 \cdot 3)$ \\
heated at $100^{\circ} \mathrm{C}$ for 10 minutes & & $9 \cdot 0(0 \cdot 8)$ & $14 \cdot 6(1 \cdot 4)$ \\
Superoxide dismutase 60 units/ml & $8 \cdot 2(0 \cdot 9)$ & $9 \cdot 2(1 \cdot 0)$ & $13 \cdot 0(0 \cdot 8)$ \\
heated at $100^{\circ} \mathrm{C}$ for 10 minutes & & $8 \cdot 3(0 \cdot 5)$ & $14 \cdot 5(1 \cdot 2)$ \\
Histidine $10 \mathrm{mmol} / 1$ & $8 \cdot 2(0 \cdot 9)$ & $8 \cdot 2(0 \cdot 5)$ & $11 \cdot 1(1 \cdot 9)^{*}$ \\
Mannitol $100 \mathrm{mmol} / 1$ & $8 \cdot 2(0 \cdot 9)$ & $8 \cdot 2(0 \cdot 5)$ & $10 \cdot 4(1 \cdot 5)$ \\
\hline
\end{tabular}

* = Significantly $(p<0.02)$ higher survival rate than in control.

experiments, although its toxic effect could be reversed by including catalase in the medium (data not shown). This suggests that its toxicity was probably due to its role in increasing the production of hydrogen peroxide from superoxide anions during the dismutase reaction rather than to any intrinsic property of the enzyme. Histidine, which is a singlet oxygen scavenger, had a protective effect on $T$ pallidum in vitro (table II). Peroxidase showed a survival enhancing effect similar to that of catalase (data not shown), which reinforced the conclusion that hydrogen peroxide is a major toxic oxygen product for $T$ pallidum. Catalase, superoxide dismutase, and mannitol were also tested in unreduced medium in $3 \%$ oxygen. The same effect was observed as under aerobic conditions, with both mannitol and catalase enhancing the survival of $T$ pallidum but with superoxide dismutase failing to do so (table III). When treponemes were incubated under anaerobic conditions in reduced medium no loss of virulence was noted until 48 hours after inoculation. The results shown above can therefore be attributed to exposure of the culture to the oxygen in the atmosphere above the medium.
PROTECTION BY OXYGEN DETOXIFYING

AGENTS UNDER HIGHLY REDUCED CONDITIONS As the reaction of reducing agents with atmospheric oxygen is known to generate toxic oxygen products, ${ }^{15} 16$ we investigated whether the generation of hydrogen peroxide or superoxide anions could be deterimental to treponemal survival under reduced conditions. The effects of three oxygen detoxifying enzymes were examined. Catalase sometimes extended survival (data not shown), but the results were not consistently better than those for the control. This may have reflected the fact that the catalase enzyme activity was inhibited by the reducing agents in the medium. Activity was only $25 \%$ of that in unreduced medium at 0 hours, and was lost completely by 48 hours. In contrast, peroxidase can use sulphydryl compounds as substrates for its reaction with hydrogen peroxide, ${ }^{31}$ and its activity was virtually $100 \%$ after three days in the reduced medium. The longer lasting activity of peroxidase was clearly beneficial to treponemal survival, particularly by 72 hours in vitro (table IV). Superoxide dismutase had no effect in the reduced medium (data not shown). Its inhibitory effect, seen under aerobic

TABLE III Effects of various oxygen detoxifying agents on $T$ pallidum survival under microaerophilic (3\% oxygen) conditions with no reducing agents present

Latent periods of syphilitic infection (days between inoculation with treponemal culture and occurrence of skin lesions) (mean (SD) of four experiments) after in vitro holding periods of:

Control (no detoxifying agents)

Mannitol $100 \mathrm{mmol} / \mathrm{l}$

Catalase 200 units $/ \mathrm{ml}$

Catalase 400 units $/ \mathrm{ml}$

Superoxide dismutase 60 units $/ \mathrm{ml}$

Superoxide dismutase 150 units $/ \mathrm{ml}$
4 hours

4 hours

$7 \cdot 0(0)$

$7 \cdot 0(0)$

$7 \cdot 2(0 \cdot 4)$

$7.0(0)$

$7 \cdot 2(0 \cdot 4)$

$7 \cdot 0(0)$

* = Significantly $(p<0 \cdot 5)$ higher survival rate than in control; NL = no lesions at 5 inoculation sites; $\uparrow=$ two lesions at five inoculation sites. 
TABLE IV Effects of various concentrations of peroxidase on $T$ pallidum survival under reduced conditions

Latent periods of syphilitic infection (days between inoculation with treponemal culture and occurrence of skin lesions) (mean (SD) of four experiments) after in vitro holding periods of:

\begin{tabular}{llllr} 
Concentration of peroxidase & 0 hours & 24 hours & 48 hours & 72 hours \\
\hline Control (no peroxidase) & $8 \cdot 5(0 \cdot 6)$ & $7 \cdot 5(0 \cdot 6)$ & $8 \cdot 2(1 \cdot 6)$ & $12 \cdot 0(0 \cdot 7)$ \\
$8 \cdot 5$ units/ml & $8 \cdot 3(0 \cdot 5)$ & $6 \cdot 3(0 \cdot 5)^{*}$ & $6 \cdot 8(0 \cdot 8)$ & $9 \cdot 2(0 \cdot 4)^{*}$ \\
17 units/ml & $8 \cdot 3(0 \cdot 5)$ & $7 \cdot 0(0 \cdot 8)$ & $6 \cdot 6(1 \cdot 3)$ & $7 \cdot 6(1 \cdot 3)^{*}$ \\
34 units/ml & $8 \cdot 0(0)$ & $7 \cdot 3(0 \cdot 5)$ & $8 \cdot 4(1 \cdot 3)$ & $8 \cdot 0(1 \cdot 0)^{*}$ \\
\hline
\end{tabular}

* = Significantly $(p<0.05)$ better survival compared with that of control.

conditions, was absent under extremely reduced conditions. Catalase, in the presence of superoxide dismutase, had no appreciable effect on treponemal survival in reduced medium.

CATALASE ACTIVITY IN $T$ PALLIDUM EXTRACTS Previous investigations have shown the presence of catalase in cell free extracts of $T$ pallidum. ${ }^{3} 17$ Because of the apparent sensitivity of $T$ pallidum to hydrogen peroxide we examined this further. Table $\mathrm{V}$ shows the levels of catalase activity in extracts from various sources and their relative mobilities in polyacrylamide gels. The activity found in the extract from $T$ pallidum had a relative mobility identical to that of catalase from rabbit fibroblasts or rabbit erythrocytes. Catalases from a variety of bacterial species all had higher relative mobilities in this system $(0 \cdot 51-0.84)$ than any of the catalases from mammalian sources $(0 \cdot 07-0 \cdot 40)$. This suggested that the catalase present in cell free extracts of $T$ pallidum was a contaminant from rabbit tissue. To confirm this, anti rabbit catalase antisera was prepared (see
Materials and methods). Fig 2 shows that the $T$ pallidum catalase activity was readily neutralised by guinea pig anti rabbit catalase. No other bands of catalase activity were present on the gels after neutralisation, which indicated that no catalase of $T$ pallidum origin was present in the extract. The guinea pig anti rabbit catalase antiserum did not neutralise catalase from $E$ coli K12 (Fig 2) or a variety of other bacterial catalases. With serum from healthy rabbits and from those which had been infected with $T$ pallidum 120 days previously there was no effect on the activity of the catalase found in the extracts of $T$ pallidum.

\section{Discussion}

The ability of living organisms to survive in the presence of oxygen directly correlates with their ability to detoxify oxygen reduction products. Obligate anaerobes do not normally have any detoxifying enzymes, aerotolerant anaerobes contain superoxide dismutase and occasionally catalase,

TABLE V Electrophoretic mobilities on polyacrylamide gels of catalases from various sources and their concentrations in cell free extracts

\begin{tabular}{llr}
\hline Source & $\begin{array}{l}\text { Relative } \\
\text { Mobility }\end{array}$ & $\begin{array}{l}\text { Units* of enzvme/mg } \\
\text { cell free e.itract }\end{array}$ \\
\hline Bovine red blood cells & $30000^{* *}$ \\
Human fibroblast (C76/203) & $0 \cdot 07$ \\
Guinea pig red blood cells & $0 \cdot 40$ \\
Rabbit testes cell culture & $0 \cdot 22$ \\
Treponema pallidum & $0 \cdot 29$ \\
Escherichia coli K12 & $0 \cdot 14$ \\
& $0 \cdot 14$ \\
Staphylococcus aureus & $0 \cdot 53$ \\
Bacillus subtilis & $0 \cdot 73$ \\
Bacillus megaterium & $0 \cdot 84$ \\
Pseudomonas aeruginosa & $0 \cdot 52$ \\
Leptospira interrogans (canicola) & $0 \cdot 72$ \\
\hline
\end{tabular}

Relative mobility $=\frac{\text { distance travelled by protein }}{\text { distance travelled by dye front }}$

$*=\mathrm{A}$ unit of activity is defined as the amount necessary to decompose $1.0 \mu \mathrm{mol} / \mathrm{l}$ hydrogen peroxide $/$ minute at $30^{\circ} \mathrm{C}$; $* *=1$ wice crystallized, purified enzyme from a commercial source (Sigma); ND = not determined; the bacterial species were harvested during stationary phase when catalase is known to be at maximal levels. ${ }^{46}$ 


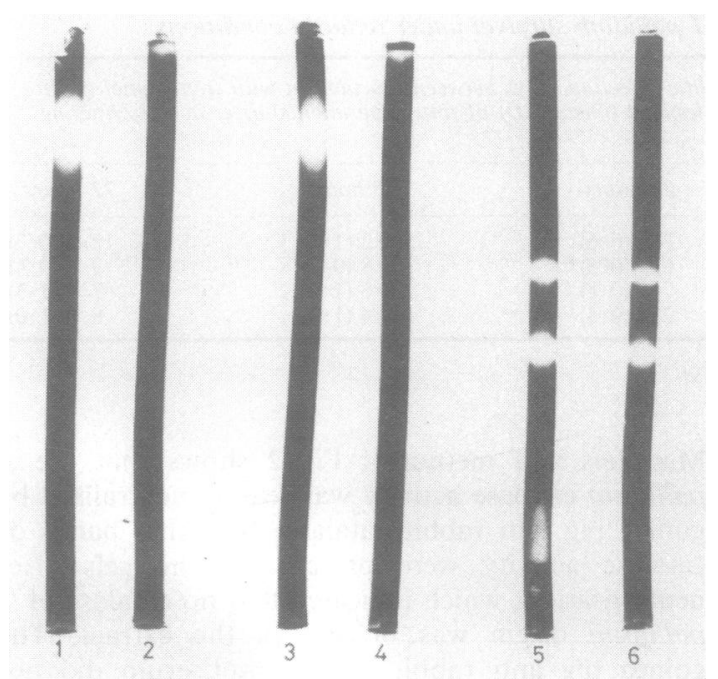

FIG 2 Polyacryımide gels after electrophoresis and staining for catalase activity, showing catalase neutralisation in cell free extracts of $T$ pallidum by guinea pig anti rabbit catalase antisera.

$I$ = partially purified rabbit catalase;

2 = partially purified rabbit catalase plus guinea pig anti rabbit catalase antiserum (catalase activity lost);

3 = concentrated cell free extract from $T$ pallidum

4 = concentrated cell free extract from $T$ pallidum plus

guinea pig anti rabbit catalase antiserum (catalase activity lost);

$5=E$ coli catalase (two bands);

$6=E$ coli catalase plus guinea pig anti rabbit catatase antiserum (no neutralisation of catalase).

while aerobes have a full complement of detoxifying enzymes. ${ }^{14}$ These defences are thought to be necessary because aerobic respiration generates various toxic reduction products, dioxygen itself being relatively non-toxic compared with reduction products. ${ }^{12}$ Utilisation of oxygen, and even increases in metabolism, are commonly seen with anaerobic organisms in the presence of oxygen. ${ }^{32}$ The generation of oxygen reduction products during respiration is the basis of their intolerance to oxygen and subsequent death. The survival of many anaerobic organisms can be enhanced by including oxygen detoxifying enzymes in the supportive medium. Catalase, for example, has been shown to protect anaerobes from the toxic effects of hydrogen peroxide. ${ }^{1533}$ Superoxide dismutase and scavengers of the hydroxyl radical, such as mannitol, formate, and thiourea can also be effective agents against oxygen damage. ${ }^{11}{ }^{34}$ Mannitol, formate, and thiourea are effective because the hydroxyl free radical (one of the most powerful oxidants known) is probably formed from hydrogen peroxide and ferric iron ions $\left(\mathrm{Fe}^{+3}\right)$ in biological systems. ${ }^{35}$

Present evidence indicates that $T$ pallidum carries $\overrightarrow{\vec{F}}$ out a respiratory form of metabolism, but is $\frac{O}{7}$ inhibited by atmospheric levels of oxygen. ${ }^{35}$ The evidence we have presented indicates that $T$ pallidum $\frac{\bar{N}}{\bar{N}}$ has a very limited ability to tolerate hydrogen $\vec{\nabla}$ peroxide and two reactive oxygen compounds which $\varrho$ can be formed from it, the hydroxyl free radical and $\&$ singlet oxygen. This sensitivity to products of normal $\vec{\circ}$ respiration would seem to preclude the possibility of this organism growing in the presence of any but the $\vec{\omega}$ lowest concentration of oxygen, at least not without the help of host enzyme functions. Less toxicity was seen with the superoxide anion, and it may only function as a propagator of the other toxic oxygen compounds in oxygen toxicity for $T$ pallidum.

The high sensitivity of $T$ pallidum to hydrogen peroxide indicates that it has a limited ability to destroy hydrogen peroxide. Lysko and $\operatorname{Cox}^{3} \mathbb{D}^{\top}$ indicated that extracts of $T$ pallidum contained catalase, and Austin et al ${ }^{17}$ recently confirmed this. We observed catalase activity in $T$ pallidum cell free extracts at levels similar to those reported, but it $\vec{\varnothing}$ proved to be a contaminant from the rabbit tissue in which the $T$ pallidum was growing (table $\mathrm{V}$ and Fig $D$ 2). The catalase seemed to be superficially associated with the treponeme as it could not be seen after trypsinisation, whereas some host superoxide dismutase was still present after this procedure (Steiner $e t$ al, unpublished observations). The substantial enhancing effect provided by added catalase suggests that treponemal bound catalase was not present in protective amounts in vitro. The catalase found in cell free extracts of $T$ pallidum might result from host cell disruption during treponemal purification, as the enzyme is intracellular in mammals. ${ }^{36} T$ pallidum evidently has no endogenous catalase and appears to have neither superoxide dismutase or peroxidase ${ }^{17}$; its apparent lack of oxygen protective enzymes may be part of the basis for its obligate parasitism.

$T$ pallidum has limited respiratory capacities and is known to contain large amounts of flavin linked $N$ enzymes. ${ }^{3}$ Many flavin linked proteins produce large $N$ amounts of hydrogen peroxide in the presence of $\mathcal{N}$ oxygen. ${ }^{37}$ Internally produced hydrogen peroxide $\omega$ may explain two requirements of $T$ pallidum in vitro: for low oxygen tensions and for reducing agent such $\stackrel{\varrho}{\subset}$ as dithiothreitol (DTT). ${ }^{78}$ Fitzgerald et al ${ }^{38}$ presented $\stackrel{\varnothing}{\mathscr{D}}$ evidence that $T$ pallidum took up DTT in vitro, showing that it may detoxify hydrogen peroxide generated internally. Reducing agents, which are commonly used in medium for $T$ pallidum, lower the level of available oxygen and thus protect against toxic oxygen reduction products. They cannot 
completely protect against oxygen damage, however, as the oxidation of the reducing agents themselves commonly results in the formation of toxic oxygen reduction products. ${ }^{15} 16$ The inability to detoxify hydrogen peroxide and reduction products resulting from it (such as the hydroxyl free radical) exposes $T$ pallidum to a large number of damaging chemical reactions. Two of the most notable are the peroxidation of membrane lipids, ${ }^{39}$ and the destructive effects of oxygen on deoxyribonucleic acid (DNA). ${ }^{40}$ Hydrogen peroxide is known to cause breakage of the DNA double helix, ${ }^{41}$ which means that DNA repair enzymes are of major importance to organisms which live in the presence of hydrogen peroxide. ${ }^{4142}$ Considering the 33 hour generation time of $T$ pallidum in vivo ${ }^{43}$ and the slow rate of activity of its known DNA polymerase(s), ${ }^{44}$ this form of defence would probably be quite feeble.

Oxygen toxicity would be reduced in tissue culture and even more in the mammalian host. $T$ pallidum is found mainly in the ground substance between cells in the tissues it parasitizes, and occasionally in the host cells. ${ }^{45}$ This sequestered environment offers a high degree of protection against oxygen toxicity, possibly more so than circulating blood. The ability to survive for at least four to eight hours in a completely aerobic milieu, as observed in our experiments, indicates that $T$ pallidum could also circulate freely in blood for extended periods of time, as is seen in the various bacteremic stages of infection with it in man. ${ }^{43}$

The prolonged survival ${ }^{4}$ and multiplication ${ }^{7}$ of $T$ pallidum observed in tissue culture is probably related to the reproduction of some of the environmental conditions found in its normal target tissues. Appreciable multiplication has only been seen to occur at oxygen tensions below $10 \% .^{7}$ Apparent growth limitations of $T$ pallidum by this method may be due to the poorer ability of tissue cultures than whole animal tissue to, remove toxic oxygen compounds. The in vivo environment that $T$ pallidum occupies, with its low oxygen tension ${ }^{36}$ and with hydrogen peroxide limited by tissue enzymes, is ideally suited in many ways to an organism with its metabolism. Whatever the factors host cells supply for the treponeme, they may be the end products of metabolic processes lost by $T$ pallidum through a long history of parasitism in its human host which has led to its obligate parasitic nature.

This work was supported by grants from the Australian National Health \& Medical Research Council, the Utah Foundation, the Heiser Program, the Australia-Britain Society, and Monash University. We thank Professor S Faine for the facilities of the Monash University microbiology department, Dr P Sutrave for many stimulating conversations relating to the preparation of this manu- script, and Linda Drummond for excellent technical assistance.

\section{References}

1. Barbieri JT, Cox CD. Influence of oxygen on respiration and glucose catabolism by Treponema pallidum. Infect Immun 1981;31:992-7.

2. Cox CD, Barber M. Oxygen uptake by Treponema pallidum. Infect Immun 1974; 10: 123-7.

3. Lysko P, Cox CD. Terminal electron transport in Treponema pallidum. Infect Immun 1977; 16:885-90.

4. Fieldsteel AH, Becker F, Stout J. Prolonged survival of virulent Treponema pallidum (Nichols strain) in cell free and tissue culture systems. Infect Immun 1977; 18: 173-82.

5. Norris S, Miller J, Sykes J. Long-term incorporation of tritiated adenine into deoxyribonucleic acid and ribonucleic acid by Treponema pallidum (Nichols strain). Infect Immun 1980;29: 1040-9.

6. Steiner B, McLean I, Graves S. Redox potential and survival of virulent Treponema pallidum under microaerophilic conditions. Br J Vener Dis 1981;57:295-301.

7. Fieldsteel AH, Cox DL, Moeckli RA. Further studies on replication of virulent Treponema pallidum in tissue culture of SflEp cells. Infect Immun 1982;35:449-55.

8. Norris S, Miller J, Sykes J, Fitzgerald TJ. Influence of oxygen tension, sulfhydryl compounds and serum on the motility and virulence of Treponema pallidum (Nichols strain) in a cell-free system. Infect Immun 1978; 22:689-97.

9. Fitzgerald TJ, Miller J, Sykes J. Treponema pallidum (Nichols strain) in tissue-cultures; cellular attachment, entry and survival. Infect Immun 1975; 11:1133-40.

10. Fitzgerald TJ, Johnson RC. Surface mucopolysaccharides of Treponema pallidum. Infect Immun 1979; 24:244-51.

11. Morris JG. The physiology of obligate anaerobiosis. In: Rase $\mathrm{AH}$, Tempest DE, eds. Advances in microbial physiology. London: Academic Press, 1975; 12: 169-246.

12. Fridovich I. Oxygen: boon and bane. Am Sci 1975; 63:54-9.

13. McCord JM, Keele BG, Fridovich I. An enzyme based theory of obligate anaerobiosis: the physiological function of superoxide dismutase. Proc Natl Acad Sci USA 1971;68: 1024-7.

14. Rolfe RD, Hentges DJ, Campbell BJ, Barret JT. Factors related to the oxygen tolerance of anaerobic bacteria. Appl Environ Microbiol 1978;36:306-13.

15. Carlsson J, Nyberg G, Wrethen J. Hydrogen peroxide and superoxide radical formation in anaerobic broth medium exposed to atmospheric oxygen. Appl Environ Microbiol 1978; 36:223-9.

16. Carlsson J, Granberg G, Nyberg G, Maj-Britt K. Bacteriocidal effect of cysteine exposed to atmospheric $\mathrm{O}_{2}$. Appl Environ Microbiol 1979; 37:383-90.

17. Austin FE, Barbieri JT, Corin RE, Grigas KE, Cox CD. Distribution of superoxide dismutase, catalase, and peroxidase activities among Treponema pallidum and other spirochaetes. Infect Immun 1981; 33:372-9.

18. Brause BD, Qualls S, Roberts RB. Testicular cultivation of Treponema pallidum (Nichols strain) facilitated by sustainedrelease steroid administration. J Clin Microbiol 1979; 10:937-9.

19. Schiller NS, Cox CD. Catabolism of glucose and fatty acids by virulent Treponema pallidum. Infect Immun 1977; 16:60-8.

20. Graves SR, Sandok PL, Jenkin HM, Johnson RC. Retention of motility and virulence in Treponema pallidum (Nichols strain) in vitro. Infect Immun 1975; 12: 1116-20.

21. Murray HW, Cohn ZA. Macrophage oxygen-dependent antimicrobial activity. I Susceptibility of Toxoplasma gondii to oygen intermediates. J Exp Med 1979; 150:938-49.

22. Dempsey PM, O'Leary J, Condon S. Polarographic assay of hydrogen peroxide accumulation in microbial cultures. Applied Microbiology 1975;29:170-4.

23. Beers RF, Sizer I. A spectrophotometric method tor measuring the breakdown of hydrogen peroxide by catalase. J Biol Chem 1952; 195: 133-40.

24. Marklund $S$, Marklund $G$. Involvement of the superoxide anion radical in the autoxidation of pyrogallol and a convenient assay for superoxide dismutase. Eur J Biochem 1974;47: 469-74. 
25. Chance B, Maehly AC. Assay of catalases and peroxidases. In: Colowick SP, Kaplan NO, eds. Methods in enzymology. New York: Academic Press, 1955; 2: 764-75.

26. Bergmeyer HU. Xanthine oxidase. In: Methods of enzymatic analysis. 2nd English Translation, Weinheim: Verlag-Chemie and New York: Academic Press, 1974.

27. Lowry OH, Rosebrough NJ, Darr AL, Randall RL. Protein measurement with the folin phenol reagent. J Biol Chem 1951; 193:265-75.

28. Davis BJ. Disc gel electrophoresis. II Method and application to human serum proteins. Ann NY Acad Sci 1964;121:404-27.

29. Woodbury W, Spencer AK, Stahlmann MA. An improved procedure using ferricyanide for detecting catalase isozymes. Anal Biochem 1971;44:301-5.

30. Bonnichsen R. Blood catalase. In: Colowick SP, Kaplan NO, eds. Methods in enzymology. New York: Academic Press, 1955; 2:781-4.

31. Olsen J, Davis $L$. The oxidation of dithiothreitol by peroxidases and oxygen. Biochim Biophys Acta 1976;445:324-9.

32. Wimpenny JWT. Oxygen and carbon dioxide as regulators of microbial growth and metabolism. In: Meadows P, Pritt S, eds. Microbial Growth. The 19th Symposium of the Society of General Microbiology. Cambridge: Cambridge University Press, 1969.

33. Harmon SM, Kauter DA. Beneficial effect of catalase treatment on growth of Clostridium perfringens. Appl Environ Microbiol 1976; 32: 409-16.

34. Cohen G. The generation of hydroxyl radicals in biological systems: toxicological aspects. Photochem Photobiol 1978; 28: 669-75.

35. Halliwell B. Superoxide-dependent formation of hydroxyl radicals in the presence of iron salts. FEBS Lett 1978;96: 238-42.
36. Chance B, Sies H, Boveris A. Hydroperoxide metabolism in mammalian organs. Physiol Rev 1979;59:527-605.

37. Strittmatter CF. Flavin-linked oxidative enzymes of Lactobacillus casei. J Biol Chem 1959;234:2794-800.

38. Fitzgerald TJ, Johnson RC, Wolff ET. Sulphydryl oxidation using procedures and experimental conditions commonly used for Treponema pallidum. Br J Vener Dis 1980;56:129-36.

39. Harley JB, Santangelo GM, Rasmussen H, Goldfine H. Dependence of hyperbaric oxygen toxicity in Escherichia coli K1060 on the lipid acyl chain composition. J Bacteriol 1978; 134: 808-20.

40. Brawn K, Fridovich I. DNA strand scission by enzymically generated oxygen radicals. Arch Biochem Biophys 1981;206: 414-9.

41. Ananthaswamy HN, Eisenstark A. Repair of hydrogen peroxide-induced single-stranded breaks in Escherichia coli deoxyribonucleic acid. J Bacteriol 1977; 130: 187-91.

42. Carlsson J, Carpenter VS. The rec $\mathrm{A}^{\dagger}$ gene product is more important than catalase and superoxide dismutase in protecting Escherichia coli against hydrogen peroxide toxicity. J Bacteriol 1980; 142:319-21.

43. Turner TB, Hollander DH. Biology of the treponematoses. WHO Monogr Ser 1957; No. 35.

44. Baseman J, Nichols J, Mogerley S. Capacity of virulent Treponema pallidum (Nichols) for deoxyribonucleic acid synthesis. Infect Immun 1979; 23:392-7.

45. Azar HA, Pham TD, Kurban AT. An electron microscopic study of a syphilitic chancre. Archives of Pathology 1970;90: 143-50.

46. Finn GJ, Condon S. Regulation of catalase synthesis in Salmonella typhimurium. J Bacteriol 1975; 123:570-9. 